\title{
Aggregation by fragilis and non-fragilis Bacteroides strains in vitro
}

\author{
M. BLAKE*§, O. D. ROTSTEINt, M. LLANO*, M. J. GIROTTIt and G. REID*t‡ \\ -Urology Research, †Department of Surgery, Toronto General Hospital, University of Toronto; and $\ddagger$ Department \\ of Microbiology, University of Toronto, Ontario, Canada
}

\begin{abstract}
Summary. Bacteroides fragilis is associated with the formation of intra-abdominal abscesses, whereas other Bacteroides species are rarely involved. Since bacterial clumping may contribute to the survival of bacteria in the face of host defence mechanisms, the hypothesis has been put forward that differences in aggregation between fragilis and non-fragilis strains of Bacteroides may account for their differences in survival in vivo. All seven $B$. fragilis strains tested formed aggregates within $4 \mathrm{~h}$, but strains not associated with intra-abdominal sepsis-- $B$. vulgatus, $B$. thetaiotaomicron and $B$. distasonis - did not form aggregates in vitro. Aggregation occurred at $37^{\circ} \mathrm{C}$, but not at $4^{\circ} \mathrm{C}$ or $20^{\circ} \mathrm{C}$. Treatment with pronase partially inhibited aggregation. Periodate treatment killed the cells and caused them to form clumps which were distinguishable from the control aggregates. Heat-killed $B$. fragilis cells formed similar distinct clumps, but cells killed by glutaraldehyde and formaldehyde did so to a lesser degree. No inhibition was found upon addition of carbohydrates, ethylenediaminetetraacetic acid or after treatment with trypsin. These results demonstrate that aggregate formation occurs with $B$. fragilis strains alone, and that surface proteins probably mediate this interaction.
\end{abstract}

\section{Introduction}

Microbiological studies of intra-abdominal infection following perforation of the colon reveal a mixture of aerobic and anaerobic bacteria (Lorber and Swenson, 1975). Bacteroides fragilis is the most frequently isolated anaerobe despite the fact that it ranks relatively low in frequency among the anaerobic bacteria present in the colonic flora (Finegold et al., 1974; Gorbach and Bartlett, 1974). Several explanations have been advanced to account for the unique survival characteristics of this particular Bacteroides species. These include its ability to resist phagocytosis by host cells (Onderdonk et al., 1977), its capacity to elaborate proteolytic enzymes (Rudek and Haque, 1976; Steffen and Hentges, 1981) and its enhanced oxygen tolerance (Tally et al., 1977).

The ability of bacteria to form aggregates has

Received 4 May 1988; accepted 28 July 1988.

‡Correspondence should be sent to Dr G. Reid, Urology Research, Bell Wing G-631, Toronto General Hospital, 200 Elizabeth Street, Toronto, Ontario, Canada M5G 2 C4.

$\S \mathrm{Mr} \mathrm{M}$. Blake is currently at the College of Surgeons, Dublin, Eire. been considered to be a virulence factor as well as a protective mechanism against killing by host phagocytes (Costerton et al., 1985), and against antimicrobial therapy (Nickel et al., 1985). Furthermore, it may represent an efficient means of transferring nutrients and maintaining a microenvironment suitable for microbial survival (Onderdonk et al., 1979). The purpose of the present study was to examine the ability of $B$. fragilis to aggregate in vitro as a potential mechanism for its persistence in vivo and its tendency towards abscess formation.

\section{Materials and methods}

\section{Bacteria and growth conditions}

The strains examined included: clinical isolates of $B$. fragilis-strains $9032,6712, \mathrm{~A}-73,36, \mathrm{~A}-460$ and 484 and type strain ATCC 25385; clinical isolates of $B$. vulgatus - strains A-541, A-374, and 00-and type strain ATCC 29327; clinical isolates of $B$. thetaiotaomicronstrains 34 and 38-and type strain ATCC 29741; and one isolate of $B$. distasonis, strain 5346. All strains except $B$. fragilis 9032 were obtained from Dr R. Devlin, Department of Microbiology, Toronto General Hospital. 
B. fragilis 9032 was obtained from Dr T. Wilkins, Virginia Polytechnic Institute, Blacksburg, VA. Stock cultures of all strains were maintained at $-70^{\circ} \mathrm{C}$ in Thioglycolate Broth (BBL Microbiology Systems, Cockeysville, MD, USA). Frozen cultures were thawed and $0.1 \mathrm{ml}$ samples were inoculated into tubes containing $10 \mathrm{ml}$ of minimal growth medium as previously described (Namavar et al., 1983; Rotstein et al., 1987). The tubes were incubated for $24 \mathrm{~h}$ at $35^{\circ} \mathrm{C}$ in an anaerobic chamber (Forma Scientific, Marietta, $\mathrm{OH}$, USA) which maintained an atmosphere of $\mathrm{N}_{2} 85 \%, \mathrm{H}_{2} \quad 10 \%, \mathrm{CO}_{2} 5 \%$. The organisms were harvested by centrifugation at $3000 \mathrm{rpm}$ for $25 \mathrm{~min}$ and were resuspended in pre-reduced phosphate-buffered saline (PBS, $\mathrm{pH} 7 \cdot 1$ ) to give concentrations ranging from $10^{7}$ to $10^{10} \mathrm{cfu} / \mathrm{ml}$. Viable counts were performed by serial dilution and plating on supplemented Brain Heart Infusion Agar. Plates were incubated anaerobically for $48 \mathrm{~h}$ at $35^{\circ} \mathrm{C}$ before colonies were counted.

\section{Aggregation assay}

A $500-\mu$ l volume of bacterial suspension was added to the well of a microtitration tray ( 24 wells; Nunclon, Denmark) and dispersed by passage through a 25 -gauge needle (Neolus, Terumo, Japan). The bacteria were incubated either anaerobically (Gas Pak jar) or aerobically at $37^{\circ} \mathrm{C}$ in a shaker (100 rpm). An observer who was unaware of the identity of the strain under test measured aggregation by examination of the cells at various times under the $10 \times$ lens of a dissecting microscope. The scoring system was based on a yisual measurement of 0 (no aggregation; fig. 1)-4 (large macroscopic clumps; fig. 2 ), in a similar fashion to that reported previously (Reid et al., 1988).

It is noteworthy that the morphology of various strains differed somewhat as determined by microscopy of Gram's stain. Although the strains illustrated in figs. 1 and 2 were both gram-negative bacilli, the $B$. thetaiotaomicron strain (fig. 1) was generally shorter, broader and more homogeneous than the $B$. fragilis strain, which was long and pleomorphic (fig. 2). This may account for the somewhat more rounded appearance of the strain illustrated in fig. 1. However, an electronmicroscopy study of $B$. fragilis $9032, B$. vulgatus A541 and B. vulgatus 29327 showed no obvious morphological differences between strains (data not shown).

\section{Effect of various agents on aggregation}

The effect of lactose, glucose, galactose, mannose, methylglucopyranoside and glucuronic acid was studied by adding $250 \mu \mathrm{l}$ of $0 \cdot 18 \mathrm{M}$ solution of the sugar to $500 \mu \mathrm{l}$ of a suspension containing $10^{9} \mathrm{cfu}$ of dispersed bacteria at the beginning of the incubation period. Aggregation was compared to that of the control in which $250 \mu \mathrm{l}$ of PBS was substituted for the sugar solution. Ethylenediaminetetraacetic acid (EDTA), at a concentration of $2.5 \mathrm{~mm}$ and adjusted to $\mathrm{pH} 7.8$ with $\mathrm{NaOH}$, was also tested in the aggregation mixture. Trypsin and pronase were made up to $2 \mathrm{mg} / \mathrm{ml}$ in distilled water and the $\mathrm{pH}$ adjusted to 7.8 with $\mathrm{NaOH} ; 1 \mathrm{ml}$ of the bacterial suspension was centrifuged and resuspended in the protease solutions, shaken for $45 \mathrm{~min}$ at $37^{\circ} \mathrm{C}$, centrifuged, and resuspended in PBS before assay. Bacterial suspensions were treated with sodium periodate $(0.001 \mathrm{M}$, $0.01 \mathrm{M}$ and $0.1 \mathrm{M}$ respectively) for $30 \mathrm{~min}$ at room temperature, added to glycerin and then washed three times in PBS before assay.

\section{Effect of bacterial killing on aggregation}

The bacteria were heat killed by exposure to : (a) $121^{\circ} \mathrm{C}$ for $15 \mathrm{~min}$; (b) $100^{\circ} \mathrm{C}$ for $30 \mathrm{~min}$; and (c) $80^{\circ} \mathrm{C}$ for 60

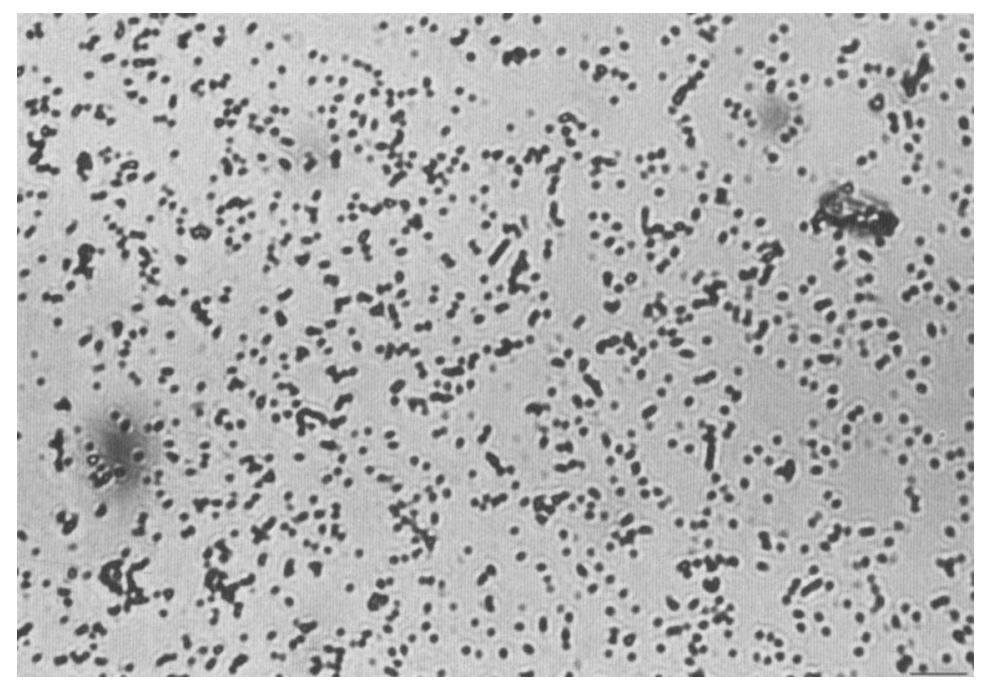

Fig. 1. Micrograph of $B$. thetaiotaomicron 38 taken on a Zeiss microscope with a $\times 40$ objective lens. The bacteria are a little out of focus due to difficulties in photographing the wet mount preparation. There is no evidence of aggregation, although some dividing cells in twos and threes are seen. Bar $=c .2 \mu \mathrm{m}$. 


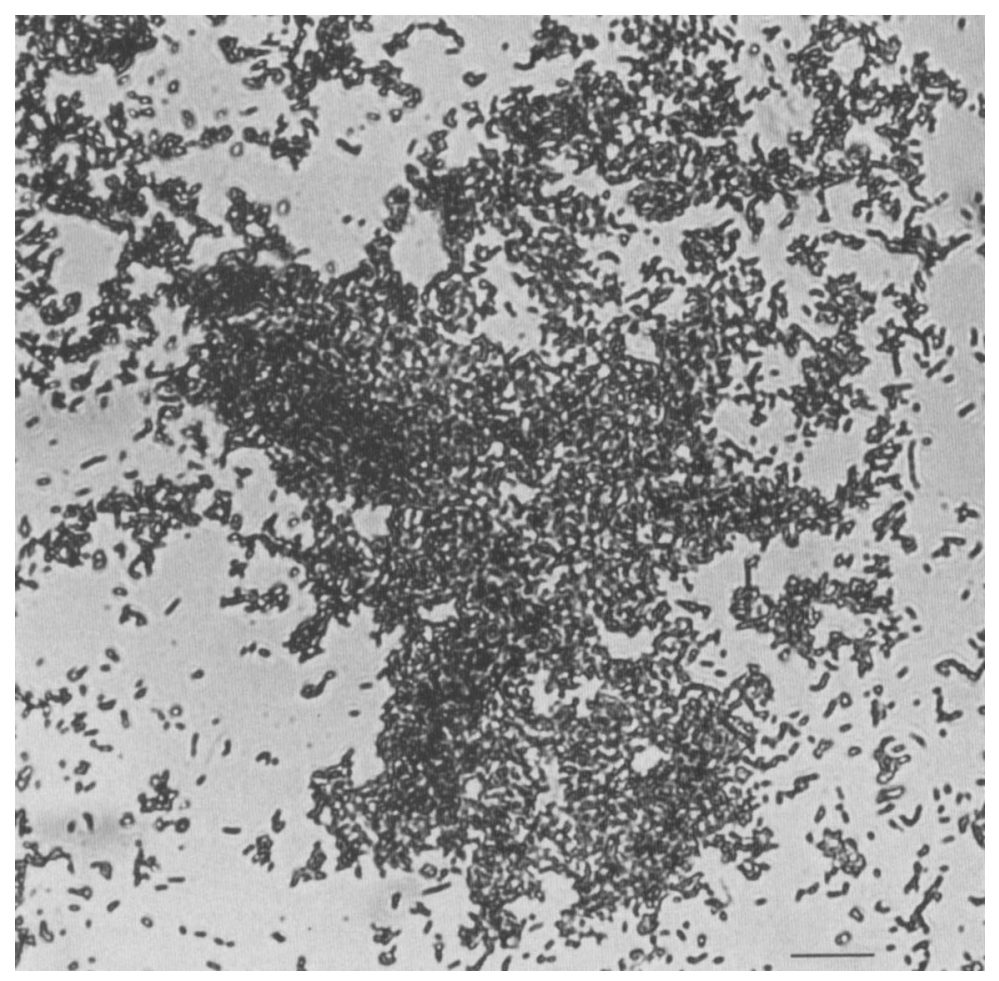

Fig. 2. Micrograph of $B$. fragilis 9032 taken on a Zeiss microscope with a $\times 40$ objective lens. There is strong, macroscopically visible aggregation-score 3 . Large clumps of aggregated cells are evident. Bar $=c .3 \mu \mathrm{m}$.

min; and then tested for aggregation. In addition, bacterial suspensions were killed by the addition of gluteraldehyde $10 \%$ for $45 \mathrm{~min}$, and formaldehyde $5 \%$ and $10 \%$ for $20 \mathrm{~min}$; they were washed three times and then tested for their ability to form aggregates.

\section{Results}

\section{Aggregation of $B$. fragilis and non-fragilis}

\section{Bacteroides}

Aggregation of $B$. fragilis 9032 occurred in a dose dependent fashion, ranging from a score of 3 at $10^{9} \mathrm{cfu} . \mathrm{ml}$ to a score of 1 at $10^{8} \mathrm{cfu} / \mathrm{ml}$ and none at $10^{7} \mathrm{cfu} / \mathrm{ml}$. Aggregation was similar whether determined at 4 or $20 \mathrm{~h}$ and whether performed under aerobic or anaerobic conditions. Aggregation was also temperature dependent. $B$. fragilis incubated at $4^{\circ} \mathrm{C}$ demonstrated poor aggregation (score 1 ) and only moderate aggregation when incubated at $20^{\circ} \mathrm{C}$ (score 2).

To compare aggregation between several different Bacteroides strains, each strain, at a concentration of $10^{9} \mathrm{cfu} / \mathrm{ml}$ was incubated for $20 \mathrm{~h}$ at $37^{\circ} \mathrm{C}$ in anaerobic conditions. All seven $\boldsymbol{B}$. fragilis strains tested produced dense aggregates at both 4 and $20 \mathrm{~h}$. Conversely, only two non-fragilis strains aggregated: $B$. vulgatus A-541 produced moderate aggregation and the type strain of $B$. vulgatus demonstrated only minimal aggregation (table I). Viability checks of the aggregates confirmed the presence of living bacteria.

\section{Effect of various agents on aggregation}

The addition of carbohydrates or the calcium chelating agent, EDTA, had no effect on the ability of $B$. fragilis to aggregate (table II). Trypsin failed to inhibit aggregation, whereas pronase caused a marked reduction in the clumping effect. Of all the agents used, pronase caused the most inhibition. The effect of periodate on bacterial aggregation was difficult to score with the standard scoring system. Although bacteria clearly aggregated, the appearance of the aggregate differed from untreated $B$. fragilis in that treated cells produced large debrislike clumps which settled on the bottom of the well. 
Table I. Aggregation scores for Bacteroides spp. tested in vitro*

\begin{tabular}{|c|c|c|c|}
\hline Strain & $\begin{array}{l}\text { Aggregation } \\
\text { score }\end{array}$ & Strain & $\begin{array}{l}\text { Aggregation } \\
\text { score }\end{array}$ \\
\hline $\begin{array}{l}\text { B. fragilis } 9032 \\
\text { B. fragilis } 6712 \\
\text { B. fragilis A460 } \\
\text { B. fragilis A73 } \\
\text { B. fragilis } 36 \\
\text { B. fragilis } 25385 \\
\text { B. fragilis } 484\end{array}$ & $\begin{array}{l}3 \\
3 \\
3 \\
3 \\
3 \\
3 \\
2 \\
3\end{array}$ & $\begin{array}{l}\text { B. vulgatus A541 } \\
\text { B. vulgatus } 29327 \\
\text { B. vulgatus A } 374 \\
\text { B. vulgatus } 00 \\
\text { B. thetaiotaomicron } 38 \\
\text { B. thetaiotaomicron } 34 \\
\text { B. thetaiotaomicron } 29741 \\
\text { B. distasonis } 5346\end{array}$ & $\begin{array}{l}2 \\
1 \\
0 \\
0 \\
0 \\
0 \\
0 \\
0\end{array}$ \\
\hline
\end{tabular}

*Based upon an inoculum of $500 \mu \mathrm{l}$ from a suspension of $10^{9} \mathrm{cfu} / \mathrm{ml}$ incubated for $4 \mathrm{~h}$ at $37^{\circ} \mathrm{C}$ in an anaerobic environment (similar results were obtained aerobically).

Score $0=$ no aggregation; $1=$ small aggregates; $2=$ larger aggregates; $3=$ macroscopic aggregates; $4=$ large clumps of macroscopic aggregates.

Periodate, at all concentrations tested, killed $B$. fragilis.

\section{Aggregation of dead cells}

To determine whether bacterial killing could account for the altered appearance of the aggregate,

Table II. The effect of various treatments on the ability of $B$. fragilis 9032 to form aggregates in vitro when the inoculum was a $10^{9} \mathrm{cfu} / \mathrm{ml}$ suspension

\begin{tabular}{lc}
\hline Treatment & $\begin{array}{c}\text { Aggregation } \\
\text { score }\end{array}$ \\
\hline Control 9032 in buffer & \\
at $37^{\circ} \mathrm{C}$ & 3 \\
at $20^{\circ} \mathrm{C}$ & 2 \\
at $4^{\circ} \mathrm{C}$ & 1 \\
Carbohydrates: & 3 \\
Lactose & 3 \\
glucose & 3 \\
galactose & 3 \\
mannose & 3 \\
methylglucopyranoside & 3 \\
glucuronic acid & 3 \\
EDTA & $1^{*}$ \\
Periodate & 3 \\
Trypsin & 1 \\
Pronase & 2 \\
Gluteraldehyde $10 \%$ & 1 \\
Formaldehyde $5 \% \%$ & 1 \\
Heat: $121^{\circ} \mathrm{C}, 15 \%$ min & $0^{*}$ \\
$100^{\circ} \mathrm{C}, 30 \mathrm{~min}$ & $0^{*}$ \\
$80^{\circ} \mathrm{C}, 60 \mathrm{~min}$ & $0^{*}$ \\
\hline
\end{tabular}

*Cell debris settled to bottom of the well, but appearance differed from aggregation.

The scoring system is described in the footnote to table I.
B. fragilis cells were killed by various techniques and tested for their ability to aggregate. Heat treatment caused the dead cells to settle on the bottom of the well, as a large clump similar to that noted for periodate-treated cells. There was no difference between the three heat treatment regimens. Glutaraldehyde and formaldehyde pretreatments caused clumping to a lesser degree so that they could still be assessed for their effect on aggregation. Glutaraldehyde partially inhibited aggregation, while formaldehyde-killing completely inhibited the aggregation.

\section{Discussion}

Strains of $B$. fragilis are the most frequently recovered anaerobic micro-organisms in intra-abdominal infections despite being greatly outnumbered in the gastrointestinal tract by non-fragilis strains (Finegold et al., 1974). This phenomenon suggests that $B$. fragilis has some unique survival characteristics which account for its persistence in these infections. Compared to non-fragilis strains, strains of $B$. fragilis have demonstrated enhanced resistance to phagocytosis by neutrophils in vitro (Onderdonk et al., 1977), and greater adherence to peritoneal surfaces in vivo (Onderdonk et al., 1978). These properties have generally been attributed to capsulation and, in particular, to the possession of a unique polysaccharide capsule. However, studies by Pruzzo et al. (1984) have suggested that fimbriae present on non-capsulate Bacteroides strains are important mediators of adherence. $B$. fragilis strains also exhibit enhanced oxygen tolerance compared to non-fragilis strains, probably as a result of their ability to produce superoxide dismutase (Tally et $a l .$, 1977). This enzyme is capable of degrading 
oxygen radicals toxic to the cell in an aerobic environment.

One further potential mechanism for survival of fragilis strains is their ability to form clumps, a means by which bacteria can resist killing by antimicrobial agents as well as phagocytic killing by host cells (Costerton et al., 1985; Nickel et al., 1985). In addition, clumping of bacteria may create optimal conditions locally for survival in an aerobic environment such as the peritoneal cavity. Coaggregation of bacteroides actinomyces and streptococci has been reported in the oral cavity (Kolenbrander et al., 1985) where bacterial interactions are associated with plaque formation (Ellen and Balcerzak-Rackowski, 1977). In support of the concept that aggregation may, at least in part, account for the persistence of fragilis strains of Bacteroides in the peritoneum, all seven fragilis strains tested aggregated in vitro, whereas only two of seven non-fragilis strains did so. Aggregation by $B$. fragilis 9032 was dose dependent in both aerobic and anaerobic conditions. This aggregation was probably not mediated via lectin binding because carbohydrates were not inhibitory. However, treatment with pronase impaired aggregation, which suggests a potential role for protein adhesins in the mechanism of aggregation. In keeping with this hypothesis, $B$. fragilis, killed by formaldehyde or glutaraldehyde, aggregated much less or not at all, presumably as a result of denaturation or fixation of surface proteins.

Sodium periodate was tested to determine the contribution of surface polysaccharide to the aggre-

\section{REFERENCES}

Cook R L, Harris R J, Reid G 1988 Effect of culture media and growth phase on the morphology of lactobacilli and on their ability to adhere to epithelial cells. Current Microbiology 17: 159-166.

Costerton J W, Marrie T J, Cheng K J 1985 Phenomena of bacterial adhesion. In: Savage D C, Fletcher $\mathbf{M}$ (eds) Bacterial adhesion: mechanisms and physiological significance. Plenum Press, New York, p 3-43.

Ellen R P, Balcerzak-Rackowski I B 1977 Interbacterial aggregation of Actinomyces naeslundii and dental plaque streptococci. Journal of Periodontal Research 12:11-20.

Finegold S M, Attebery H R, Sutter V L 1974 Effect of diet on human fecal flora: Comparison of Japanese and American diets. American Journal of Clinical Nutrition 27: 1456-1469.

Gorbach S L, Bartlett J G 1974 Medical progress. Anaerobic infections. New England Journal of Medicine 290:11771184 .

Kolenbrander P E, Andersen R N, Holdeman L V 1985 Coaggregation of oral Bacteroides species with other gation process. At all concentrations tested, periodate killed the bacteria, causing them to clump at the bottom of the well in a pattern which was clearly different from aggregation. Vel et al. (1986) have reported that similar concentrations of periodate prevented haemagglutination of several Bacteroides strains. However, these authors did not report on the viability of cells following periodate treatment.

All strains grew well in the culture medium used in these studies, but there was variation among strains. The effect of growth conditions on aggregation was not investigated in the present studies. However, these have been demonstrated to affect bacterial morphology and adhesion (Cook et al., 1988) and will be the subject of future studies related to Bacteroides.

The present studies demonstrated a significant degree of aggregation among $B$. fragilis strains but the phenomenon was largely absent among nonfragilis strains. There was some evidence to suggest that the aggregation process appeared to be mediated via a surface protein adhesin. Whether aggregation itself serves to enhance survival of fragilis strains over non-fragilis strains by impeding host clearance of these bacteria, or by some other mechanism, will be the subject of further study.

This work was supported by the Medical Research Council of Canada, and the Kidney Foundation of Canada. We thank Drs R. Power and A. W. Bruce for their support, direction and encouragement, Dr R. L. Cook, Ms Kim Houston, and Mr J. $\mathrm{Kao}$, for their technical assistance, and Miss Christina Wareham for preparation of the manuscript. bacteria : central role in coaggregation bridges and competitions. Infection and Immunity 48:741-746.

Lorber B, Swenson R M 1975 The bacteriology of intraabdominal infections. Surgical Clinics of North America 55: 1349-1354.

Namavar F, Verweij A M J J, Bal M, van Steenbergen T J M, de Graaff J, MacLaren D M 1983 Effect of anaerobic bacteria on killing of Proteus mirabilis by human polymorphonuclear leukocytes. Infection and Immunity 40:930-935.

Nickel J C, Ruseska I, Wright J B, Costerton J W 1985 Tobramycin resistance of Pseudomonas aeruginosa cells growing as a biofilm on urinary catheter material. Antimicrobial Agents and Chemotherapy 27:619-924.

Onderdonk A B, Kasper D L, Cisneros R L, Bartlett J G 1977 The capsular polysaccharide of Bacteroides fragilis as a virulence factor: comparison of the pathogenic potential of encapsulated and unencapsulated strains. Journal of Infectious Diseases 136:82-89.

Onderdonk A B, Kasper D L, Mansheim B L J, Louie T J, Gorbach S L, Bartlett J G 1979 Experimental animal 
models for anaerobic infections. Reviews of Infectious Diseases 1 : 291-301.

Onderdonk A B, Moon N E, Kasper D L, Bartlett J G 1978 Adherence of Bacteroides fragilis in vivo. Infection and Immunity 19: 1083-1087.

Pruzzo C, Dainelli B, Ricchetti M 1984 Piliated Bacteroides fragilis strains adhere to epithelial cells and are more sensitive to phagocytosis by human neutrophils than nonpiliated strains. Infection and Immunity 43:189-194.

Reid G, McGroarty J A, Angotti R, Cook R L 1988 Lactobacillus inhibitor production against Escherichia coli and coaggregation ability with uropathogens. Canadian Journal of Microbiology 34:344-351.

Rotstein O D, Pruett T L, Wells C L, Simmons R L 1987 The role of bacteroides encapsulation in the lethal synergy between Escherichia coli and Bacteroides species studied in a rat fibrin clot peritonitis model. Journal of Infection 15: 135-146.

Rudek W, Haque R U 1976 Extracellular enzymes of the genus Bacteroides. Journal of Clinical Microbiology 4:458-460.

Steffen E K, Hentges D J 1981 Hydrolytic enzymes of anaerobic bacteria isolated from human infections. Journal of Clinical Microbiology 14: 153-156.

Tally F P, Goldin B R, Jacobus N V, Gorbach S L 1977 Superoxide dismutase in anaerobic bacteria of clinical significance. Infection and Immunity 16:20-25.

Vel W A C, Namavar F, Verweij-van Vught A M J J, Pubben A N B, MacLaren D M 1986 Haemagglutination by the Bacteroides fragilis group. Journal of Medical Microbiology 21: 105-107. 